\title{
Developing a GIS-based Fuzzy AHP Model for Selecting Solar Energy Sites in Shodirwan Region in Iran
}

\author{
A. Asakereh, M. Omid", R. Alimardani and F. Sarmadian \\ Faculty of Agricultural Engineering and Technology, School of Agricultural \\ and Natural Resources, University of Tehran, Iran \\ *Omid@ut.ac.ir
}

\begin{abstract}
The objective of this study is to use a Fuzzy Analytic Hierarchy Process (Fuzzy AHP) and geographical mapping models using Geographical Information System (GIS) to locate the most appropriate sites for solar energy farms in Shodirwan region in Iran. GIS interpolation showed that annual solar insolation in Shodirwan is very good and can be used for potential solar farm locations. The average of solar insolation in the region is $5.12 \mathrm{kWh} / \mathrm{m} 2 /$ day annually. Results showed that $18.25 \%$ of the Shodirwan area is exploitable as solar farms. With a conversion efficiency of $10 \%$ and area factor of $70 \%$, annual electricity production for the exploitable area is roughly 16100 GWh. Land suitability analysis for solar farms implementation was carried out and overlay results obtained from the analysis of the resultant maps showed that $13.98 \%$ and $3.79 \%$ of the total land area demonstrate high and good suitability levels, respectively. The total electricity generation potential from both highly and good suitability levels in Shodirwan region was about 15,690 GWh annually.
\end{abstract}

Keywords: Fuzzy AHP, GIS, Site selection, Solar energy, Solar radiation, Spatial analysis

\section{Introduction}

The interest on renewable energies is growing day by day, as fossil fuels become more expensive and difficult to find than before. Furthermore, the latest environmental disasters caused by the oil drilling and transportation, have further focused the attention of the entire world on the risks connected to fossil fuels [1]. The utilization of nonrenewable energy sources in the developing countries with low levels of technological knowledge not only results in environmental pollution but also confronts us with the dilemma of a rapid rate of depletion of such invaluable resources [2, 3]. Moreover, life of oil reserves are limited and the share of next generation must be considered so that they may have better options to utilize these badly treated treasures $[2,4,5]$. New and renewable energies will, therefore, become the world's main alternative energy sources. It is expected that $60 \%$ of world energy will come from renewable energy sources by the year $2070[6,7]$.

Iran is the second Middle Eastern country with respect to enjoying various energy resources. Iran not only enjoys vast and valuable deposits of fossil fuels and natural gas which contribute to her national economy and export earnings in a major way but also is a rich country in terms of renewable energy resources such as solar, wind, geothermal, hydro, etc., where scientists and researchers have made special efforts in finding and developing renewable energy sources as well as adopting related technical

* Corresponding Author 
knowledge in processing them. One of the most interesting, among the renewable energy resources in Iran, is the solar energy. Solar energy is not only inexhaustible but also clean. As on-site sources of clean power, solar energy systems can reduce greenhouse gas (GHG) emissions and air pollution, increasing energy security and creating local jobs. It can be safely converted to other forms of energy without emitting carbon dioxide gas, thereby avoiding any greenhouse effect. The utilization of the solar radiations has a wide range of applications; nevertheless the interest of solar engineering is mainly focused on thermal processes and photovoltaic (PV) applications. During the last two decades, the rhythm of the implementation of solar farms using PV panels or Concentrated Solar Power (CSP) technologies has accelerated in the countries situated in the solar energy belt, despite their prohibitive costs. Solar electricity systems also have the potential to generate power when it is needed most-on hot summer days - thereby relieving strain on the electricity system and reducing the risk of blackouts $[1,8,9]$.

During the last decade, the use of the Geographical Information System (GIS) has accelerated in field of renewable energy in several regions of the world. GIS are computer-based systems that store and process (e.g., manipulate, analysis, model, etc.,) spatially referenced data at different points in time and visualize the results [10]. A variety of renewable energy applications have been undertaken using GIS techniques [11-19]. The GIS-based decision support systems has reached a high level of maturity and emerged as a powerful tool to build solar energy strategies and to integrate large amounts of PV into flexible, efficient and smart grid. GIS is capable of handling, processing and analyzing large quantities of spatial data and valuable in underpinning decision making for the spatial deployment of PV. Using GIS and Multi-Criteria Decision Analysis (MCDA) together will provide a fine lens for the optimal site selection for plants. GIS-based MCDA is commonly used to solve the conflicts of location suitability and harmonizing the tradeoffs and risks related to various experts' judgment engaged in the implementation of different applications [9, 20-22]. The Analytic Hierarchy Process (AHP) is a useful systematic tool for handling MCDA. AHP is a decision-aided method which decomposes a complex multi-factor problem into a hierarchical structure, and each level is composed of specific elements [23-26].

In most of the real-world problems, some of the decision data can be precisely assessed while others cannot. Fuzzy AHP is a synthetic extension of AHP method when the fuzziness of the decision makers is considered. In this study, Chang's extent analysis [27] on fuzzy AHP is formulated for a selection problem. In this study, we apply Fuzzy AHP and GIS-based mapping models to locate the most appropriate sites for solar energy in Shodirwan region in Iran.

\section{Methods and Materials}

\subsection{Fuzzy Set Theory}

In reality, it is very hard to extract precise decision data related to measurement indicators by human judgments. Decision makers and policy makers also prefer natural language expressions rather than crisp numbers. Zadeh (1965) introduced the fuzzy theory, and its first utilization for decision making problems was presented by Bellman and Zadeh's work. Fuzzy set theory has made a major contribution to representing vague and incomplete data [29] when its capability to provide a methodology for computing directly with words is considered. Fuzzy theory is composed of three key factors, which are fuzzy set, membership function, and fuzzy number to change vague data into useful data efficiently. Fuzzy numbers 
are in fact natural generalizations of ordinary numbers. Triangular and trapezoidal fuzzy numbers are usually used to capture the vagueness of the parameters which are related to selecting the alternatives [26, 30-32]. In this research, we used triangular and trapezoidal to prioritize suitability of land for solar energy sites. Triangular and trapezoidal fuzzy numbers are expressed with boundaries instead of crisp numbers for reflecting the fuzziness as decision makers select the alternatives or pairwise comparisons matrix.

A fuzzy number $\mathrm{M}$ on $\mathrm{R}$ is called a triangular fuzzy number (TFN) if its membership function is given by $[26,27]$ :

$\mu_{\dot{a}}(x)=R \rightarrow[0,1]$
$\mu_{\tilde{a}}(x)= \begin{cases}\frac{x}{m-l}-\frac{l}{m-l} & x \in[l, m] \\ \frac{x}{m-u}-\frac{u}{m-u} & x \in[m, u] \\ 0 & \text { Otherwise }\end{cases}$

and we define a fuzzy number $\mathrm{M}$ on $\mathrm{R}$ to be a trapezoidal fuzzy number if its membership function is:

$\mu_{\mathrm{a}}(\mathrm{x})=\mathrm{R} \rightarrow[0,1]$
$\mu_{\dot{\alpha}}(x)=\left\{\begin{array}{lc}\frac{x}{n-l}-\frac{l}{n-l} & x \in[l, n] \\ \frac{1}{m-u}-\frac{u}{m-u} & x \in[n, m] \\ 0 & x \in[m, u]\end{array}\right.$

Consider two TFNs $\mathrm{M}_{1}$ and $\mathrm{M}_{2}, \mathrm{M}_{1}=\left(\mathrm{l}_{1}, \mathrm{~m}_{1}, \mathrm{u}_{1}\right)$ and $\mathrm{M}_{2}=\left(\mathrm{l}_{2}, \mathrm{~m}_{2}, \mathrm{u}_{2}\right)$. Their operations laws are as follows [32, 33]:

$$
\begin{aligned}
& \left(\mathrm{l}_{1}, \mathrm{~m}_{1}, \mathrm{u}_{1}\right)+\left(\mathrm{l}_{2}, \mathrm{~m}_{2}, \mathrm{u}_{2}\right)=\left(\mathrm{l}_{1}+\mathrm{l}_{2}, \mathrm{~m}_{1}+\mathrm{m}_{2}, \mathrm{u}_{1}+\mathrm{u}_{2}\right) \\
& \left(\mathrm{l}_{1}, \mathrm{~m}_{1}, \mathrm{u}_{1}\right) \times\left(\mathrm{l}_{2}, \mathrm{~m}_{2}, \mathrm{u}_{2}\right)=\left(\mathrm{l}_{1} \times \mathrm{l}_{2}, \mathrm{~m}_{1} \times \mathrm{m}_{2}, \mathrm{u}_{1} \times \mathrm{u}_{2}\right) \\
& \left(\mathrm{l}_{1}, \mathrm{~m}_{1}, \mathrm{u}_{1}\right)^{-1}=\left(\frac{1}{\mathrm{u} 1}, \frac{1}{m 1}, \frac{1}{l 1}\right)
\end{aligned}
$$

\subsection{Fuzzy AHP}

AHP is one of the well-known multicriteria decision making (MCDM) method invented by Saaty in 1970s [34]. It is the powerful and useful MCDM approach tool. Saaty suggested the AHP as a decision making tool to resolve unstructured problems. AHP is based on pairwise comparisons. In this method, decision-maker forms a hierarchical decision tree and determines its indices and options. Although the AHP method is to capture the expert's knowledge by perception or preference, AHP still cannot reflect the human thoughts totally with crisp numbers as compared to fuzzy AHP method due to its interval values instead of simple crisp numbers. Therefore, the fuzzy AHP, which is a fuzzy extension of AHP, is applied to solve the hierarchical fuzzy MCDM problems. There are numerous cases for employing fuzzy AHP. The extend analysis method (EA) was presented in 1996 by Chang [27]. TFN is used in this model.

Let $\mathrm{M}_{\mathrm{i}}=\left(\mathrm{l}_{\mathrm{ij}}, \mathrm{m}_{\mathrm{ij}}, \mathrm{u}_{\mathrm{ij}}\right)$ be a TFN. The stages of extent analysis approach can be summarized as follows:

Letting $C_{j}=\left\{C_{1}, C_{2}, ., C_{n}\right\}$ be a criteria set, extent analysis values for each criterion can be obtained as follows [27, 32]:

$$
\begin{aligned}
& S_{i}=\sum_{j=1}^{m} M_{i j} \times\left[\sum_{i=1}^{n} \sum_{j=1}^{m} M_{i j}\right]^{-1} \\
& \text { s.t } \sum_{j=1}^{m} M_{i j}=\left(\sum_{j=1}^{m} l_{i j}, \sum_{j=1}^{m} m_{i j}, \sum_{j=1}^{m} u_{i j}\right) \text { for } i=1,2, \ldots, n
\end{aligned}
$$




$$
\begin{aligned}
& \sum_{i=1}^{n} \sum_{j=1}^{m} M_{i j}=\left(\sum_{i=1}^{n} \sum_{j=1}^{m} l_{i j}, \sum_{i=1}^{n} \sum_{j=1}^{m} m_{i j}, \sum_{i=1}^{n} \sum_{j=1}^{m} u_{i j}\right) \\
& {\left[\sum_{i=1}^{n} \sum_{j=1}^{m} M_{i j}\right]^{-1}=\left(\frac{1}{\sum_{i=1}^{n} \Sigma_{j=1}^{m} u_{i j}}, \frac{1}{\sum_{i=1}^{m} \sum_{j=1}^{m} m_{i j}}, \frac{1}{\sum_{i=1}^{n} \Sigma_{j=1}^{m} l_{i j}}\right)}
\end{aligned}
$$

As $S_{j}=\left(l_{j}, m_{j}, u_{j}\right)$ and $S_{i}=\left(l_{i}, m_{i}, u_{i}\right)$ are two triangular fuzzy numbers, the degree of possibility of $S_{j}=\left(l_{j}, m_{j}, u_{j}\right) \geq S_{i}=\left(l_{i}, m_{i}, u_{i}\right)$ is defined as:

$$
V\left(S_{j} \geq S_{i}\right)=\text { height }\left(S_{i} \cap S_{j}\right)=u_{S_{j}}(d)=\left\{\begin{array}{cc}
1 & \text { if } m_{j} \geq m_{i} \\
0 & \text { if } l_{i} \geq u_{j} \\
\frac{l_{i}-u_{j}}{\left(m_{j}-u_{j}\right)-\left(m_{i}-l_{i}\right)} & \text { Otherwise }
\end{array}\right.
$$

where $\mathrm{d}$ is the ordinate of the highest inter section point between $u_{\mathrm{Si}}$ and $u_{\mathrm{Sj}}$. We need to compare both the values of $\mathrm{V}\left(\mathrm{S}_{\mathrm{j}} \geq \mathrm{S}_{\mathrm{i}}\right)$ and $\mathrm{V}\left(\mathrm{S}_{\mathrm{i}} \geq \mathrm{S}_{\mathrm{j}}\right)$ with $\mathrm{S}_{\mathrm{i}}$ and $\mathrm{S}_{\mathrm{j}}$.

The degree possibility for a convex fuzzy number to be greater than $\mathrm{k}$ convex fuzzy Mi ( $\mathrm{i}=$ $1,2, \ldots, \mathrm{k})$ numbers can be defined by:

$\mathrm{V}\left(\mathrm{S} \geq \mathrm{S}_{1}, \mathrm{~S}_{2}, \ldots, \mathrm{S}_{\mathrm{k}}\right)=\mathrm{V}\left[\left(\mathrm{S} \geq \mathrm{S}_{1}\right)\right.$ and $\left(\mathrm{S} \geq \mathrm{S}_{2}\right)$ and....and $\left.\left(\mathrm{S} \geq \mathrm{S}_{\mathrm{k}}\right)\right]=\operatorname{Min} \mathrm{V}\left(\mathrm{S} \geq \mathrm{S}_{\mathrm{i}}\right)$, $\mathrm{i}=1,2,3, \ldots, \mathrm{k}$

Assume that $\mathrm{d}\left(\mathrm{A}_{\mathrm{i}}\right)=\min \mathrm{V}\left(\mathrm{S}_{\mathrm{i}} \geq \mathrm{S}_{\mathrm{k}}\right)$ for $\mathrm{k}=1,2, \ldots, \mathrm{n}$. Then the weight vector is given by:

$W^{\prime}=\left(d^{\prime}\left(A_{1}\right), d^{\prime}\left(A_{2}\right), \ldots, d^{\prime}\left(A_{n}\right)\right)^{T}$

where $\mathrm{A}_{\mathrm{i}}(\mathrm{i}=1,2, \ldots, \mathrm{n})$ are the $\mathrm{n}$ elements.

Via normalization, the normalized weight vectors are:

$$
W=\left(d\left(A_{1}\right), d\left(A_{2}\right), \ldots, d\left(A_{n}\right)\right)^{T}
$$

where $\mathrm{W}$ is a non-fuzzy number.

\subsection{Study Area and Data}

The study was carried out for Shodirwan region in Khuzestan province, Iran. This region is peninsula between Karun and Dez rivers and is the one of the important agriculture crop areas in Iran and most of it is a rural area. Imam Khomeini agro-Industry with about 15000 hectares located in the middle of Shodirwan that sugarcane is cultivated in it.

Reliable long-term sunshine measurements are sparse and available only for regions where meteorological stations are operating. Datasets for the solar insolation was obtained from the Iran Meteorological Organization and Renewable Energy Organization of Iran. In the regions where there are no data available the insolation has been estimated using an interpolation method of measured values from meteorological stations with similar climatological conditions. For this study 21 of stations in Khuzestan province that collect the amount of solar insolation were identified. The amount of daily solar insolation for each station is averaged over the period of establishment of stations to 2009 for each station. The data provides estimates for $\mathrm{kWh} / \mathrm{m}^{2} /$ day for each month of the year, as well as an annual average. Averaged values for each station are plotted on a map of Khuzestan province with longitude and latitude based on Universal Transverse Mercator coordinate system (UTM), and then, spatial interpolation technique, Kriging interpolation is used for predicting insolation values for unsampled locations on ArcGIS. Then map for Shodirwan region was extracted from interpolated solar insolation map. Digital databases of land cover and land use, location of roads, transmission lines, topography, and accessibility to the grid were obtained from Jahad Agriculture Organization of Khuzestan province and Iran National Cartographic Center. 


\subsection{Criteria of Appropriate Solar Sites Selection}

The first step is to eliminate inappropriate locations due to terrain or security reasons. One criterion applied in the determination of potential solar farm locations is the current land use. Solar farm installations require the majority of land to be utilized solely for these installations. As a result, the only barren land considered as permissible for solar energy that include of bedrock, desert pavement, scarps, talus, slides, volcanic material, glacial debris, sand dunes, strip mines, gravel pits and other accumulations of earthen material. Generally, vegetation accounts for less than $15 \%$ of total cover [18]. In Shodirwan region there isn't any area that is restricted due to conservation. Any area that does not barren was eliminated for solar energy generation.

Other criterions to select appropriate sites for solar energy are amount of insolation, transmission lines, topography and Distance to roads. Slope and aspect are topographic features that play important role in selecting solar energy site. Digital elevation model (DEM) represented as a raster format with a pixel of $10 \mathrm{~m}$ were obtained from Iran National Cartographic Center. The value of the pixel represents the elevation which can be used to calculate slope and aspect with ArcMap. The GIS analysis was conducted on ESRI's ArcMap 9.3 software. The value of 1 was given to any cell with slope of $0-3 \%$, and cells with slope $3-$ $10 \%$ were valued from 0 to 1 by:

$S_{\text {value }}=\left\{\begin{array}{cc}1 & x \leq 3 \\ \frac{x_{\text {slope }}-10}{-7} & 3 \leq x \leq 10 \\ 0 & \text { Otherwise }\end{array}\right.$

where $\mathrm{S}$ is any sell in slope map of Shodirwan region and $\mathrm{x}_{\text {slope }}$ is slope of $\mathrm{x}$ cell (\%). Any cell that has slope greater than $10 \%$ was assigned value of 0 .

Locations with south-facing aspects are good locations for solar farms due to the southern exposure. Aspect raster map were valued by:

$A_{\text {value }}=\left\{\begin{array}{cc}\frac{x_{\text {degres }}-112.5}{33.5} & 112.5 \leq x_{\text {degres }} \leq 146 \\ 1 & 146 \leq x_{\text {degres }} \leq 214 \\ \frac{x_{\text {degres }}-247.5}{-33.5} & 214 \leq x_{\text {degres }} \leq 247.5\end{array}\right.$

where $A_{\text {value }}$ is value that gives any cell in aspect raster map and $x_{\text {degree }}$ is aspect of any $\mathrm{x}$ cell in degree.

Road adjacency is desirable criterion in the determination of potential solar farm locations and minimum distance from road is objective. Also minimum distance from transmission lines is objective. The closeness to the transmission lines means less loss of electricity when transferring electricity through transmission lines and easier establishes grid-connected PV utility there. The straight-line distance tool of ArcGIS is used to measure distances from each location to the closest road and transmission lines and then road adjacency and grid accessibility raster maps were valued by valued by:

$D_{\text {value }}=\left\{\begin{array}{cc}1 & x_{d} \leq 1000 \\ \frac{x_{d}-1000}{39000} & 1000 \leq x_{d} \leq 40000 \\ 0 & \text { Otherwise }\end{array}\right.$

where $D_{\text {value }}$ is value that give any cell in road adjacency and grid accessibility raster maps and $\mathrm{x}_{\mathrm{d}}$ is distance of any $\mathrm{x}$ cell in meter.

To find out the most appropriate locations for solar farms in Shodirwan, slope, aspect, road adjacency and grid accessibility raster map was used in fuzzy AHP model. Pair-wise 
comparisons for criteria and judgment to the relative intensity of importance of one evaluation factor against another were calculated.

\section{Results}

The results of kriging interpolation of solar insolation for each month of the year are illustrated in Figure 1. Map of this potential will be used to prioritize the region for solar energy generation and solar site establishment. Grid cells were output at a $20 \mathrm{~m}$ resolution in raster format. The average of solar insolation in all the chosen region is $5.12 \mathrm{kWh} / \mathrm{m}^{2} /$ day annually while for each month is different. Minimum of solar insolation was related to December that ranged from 2.79 to $2.88 \mathrm{kWh} / \mathrm{m}^{2} /$ day. The greatest of solar insolation was in summer so that Jun and July had the maximum solar insolation in Shodirwan region. According to the results of interpolation of insolation data, the maximum insolation intensity per day is approximately $7.48 \mathrm{kWh} / \mathrm{m}^{2} /$ day that occur in Jun. High solar insolation and great potential of solar energy can be useful in reducing the load on the power grid and power outages in the hot summer and thereby relieving strain on the electricity system and reducing the risk of blackouts. According to solar resource potential classification by National Renewable energy Laboratory, annual solar insolation in Shodirwan is very good and can be used for potential solar farm locations [35]. Total of annual solar energy with no constraint in Shodirwan is about $1263 \mathrm{TWh}$ but due to constraint and low conversion efficiency of technology only a little of this amount of energy can be used.

A constraint layer including all the unsuitable areas was created and eliminated from Shodirwan region. The region that doesn't have constraint for solar farm installation is showed in Figure 2. In this study, the current land use and land cover that was considered suitable for solar energy, were rangeland, rocky protrusions, dry farming and salty land. Due to low rainfall, dry farming isn't successful and accordingly was considered suitable for exploiting solar energy. Also the most of rangeland is medium and low dense and was considered suitable for solar energy use. It is obvious that most of the Shodirwan area is non exploitable for solar energy use and only $18.25 \%$ of it is exploitable. Non exploitable area is composed from irrigated farming, agro-industry, rivers, Shrub land, rural and urban areas and installations, marsh land with high level of surfaces water and area with slopes more than $10 \%$, because it is not possible or not economical to build a large solar farm on buildings, marsh land or rivers.
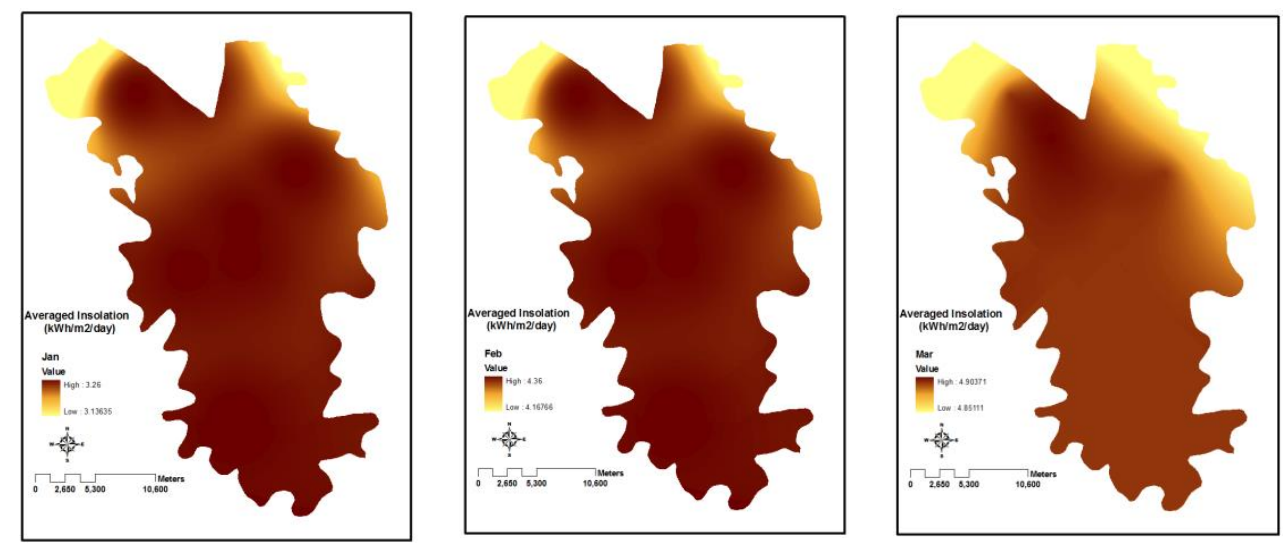

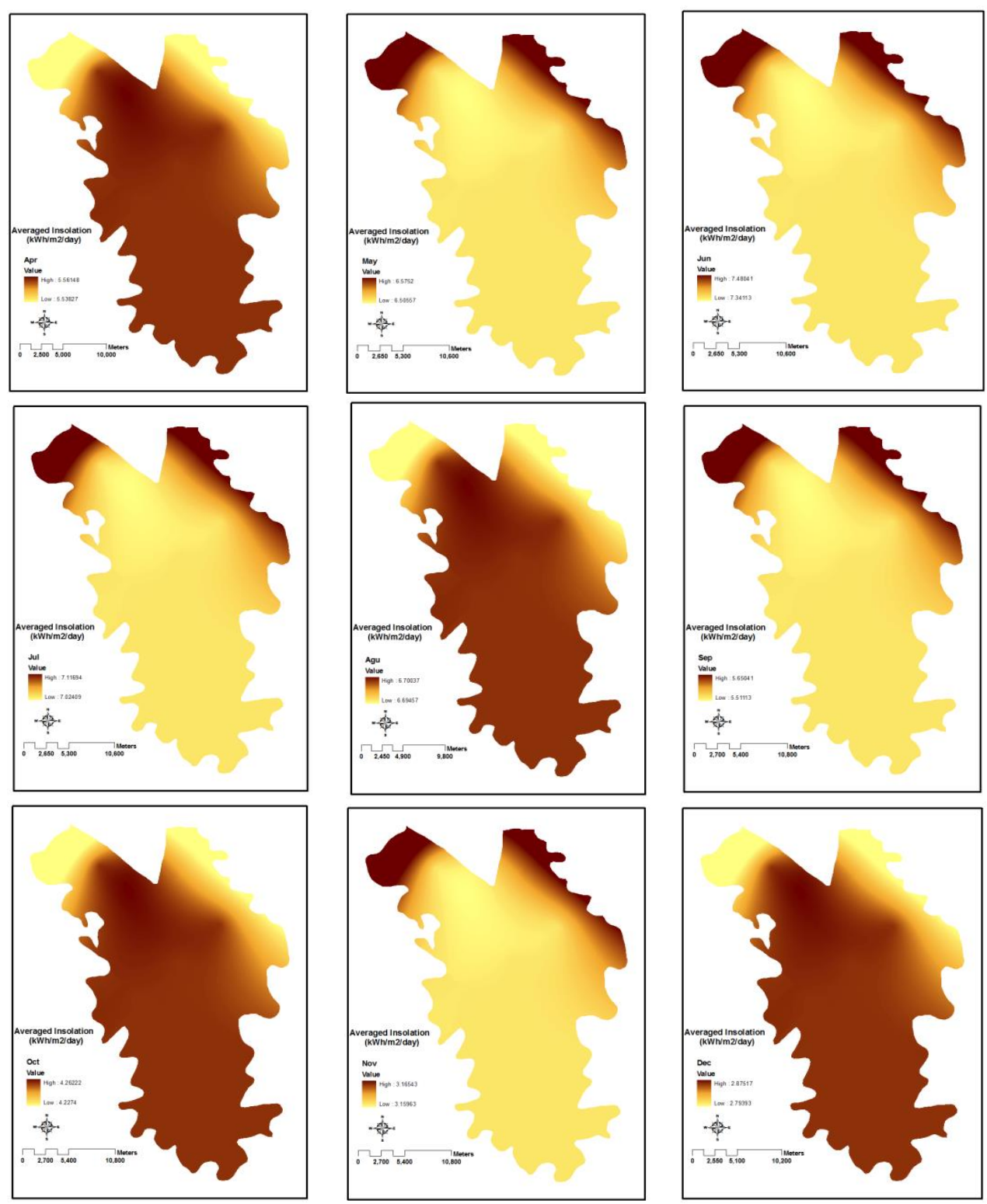

Figure 1. Monthly Solar Insolation

Annual energy that the exploitable area receives from the sun is $230 \mathrm{TWh}$ that regardless of the economy, with conversion efficiency of $10 \%$ and area factor of $70 \%$, annual electricity production for exploitable area is roughly $16100 \mathrm{GWh}$. Area factor indicates what fraction of the calculated areas can be covered by solar panels. As of 2009, the total annual net electricity consumed in agriculture sector of Khuzestan province and Iran were 695.3 and 21410.7 GWh, respectively and the total annual electricity consumed in Khuzestan province was roughly $19100 \mathrm{GWh}$ [36]. In fact, if all exploitable land is used completely for solar form implementation, it can produce almost 23.3 and 0.75 times the total electricity demand in agriculture sector of Khuzestan province and Iran, respectively and 0.84 times the total electricity demand in Khuzestan province. 


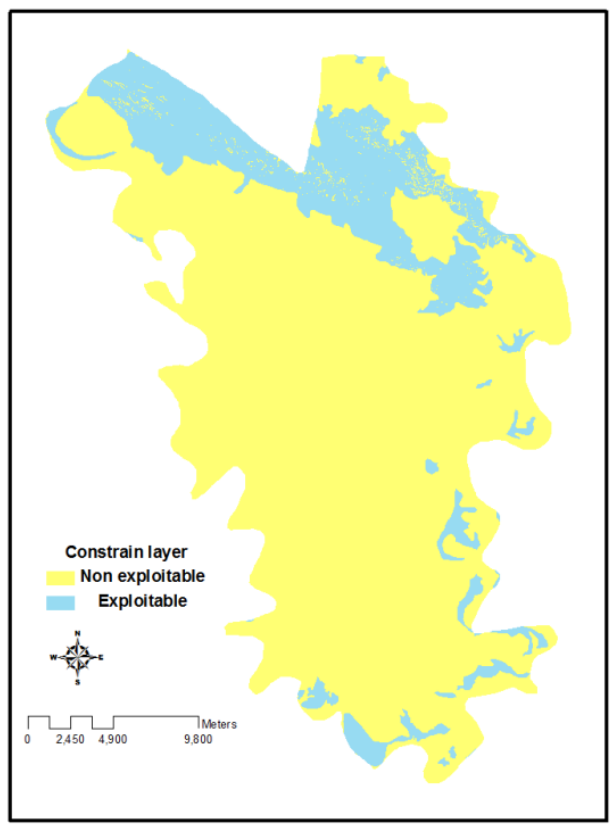

Figure 2. Constraint Layer

Fuzzy layer of criteria are illustrated in Figure 3. Road accessibility layer had values from 0.89 to 1 . About $45.3 \%$ of Shodirwan area had value of 1 . This range of fuzzy value showed that all of Shodirwan area has good accessibility to roads. In terms of access to power transmission lines, $16.54 \%$ of all Shodirwan area had a fuzzy value of 1 . Minimum value of grid accessibility was 0.59 . Most of Shodirwan region is flat so that only $0.63 \%$ of its slope is greater than $10 \%$ and about $93.22 \%$ its slope is less than $3 \%$ with fuzzy value of 1 . Also, due to the flatness of the land, most areas have a fuzzy value of 1 for aspect. Aspect of fuzzy value ranged from 0 to 1 .
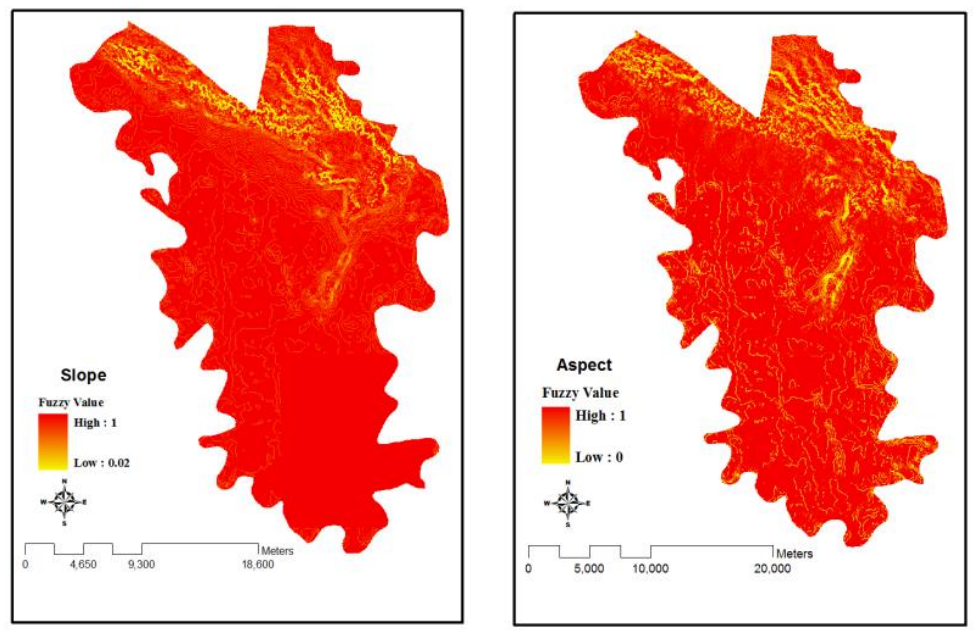

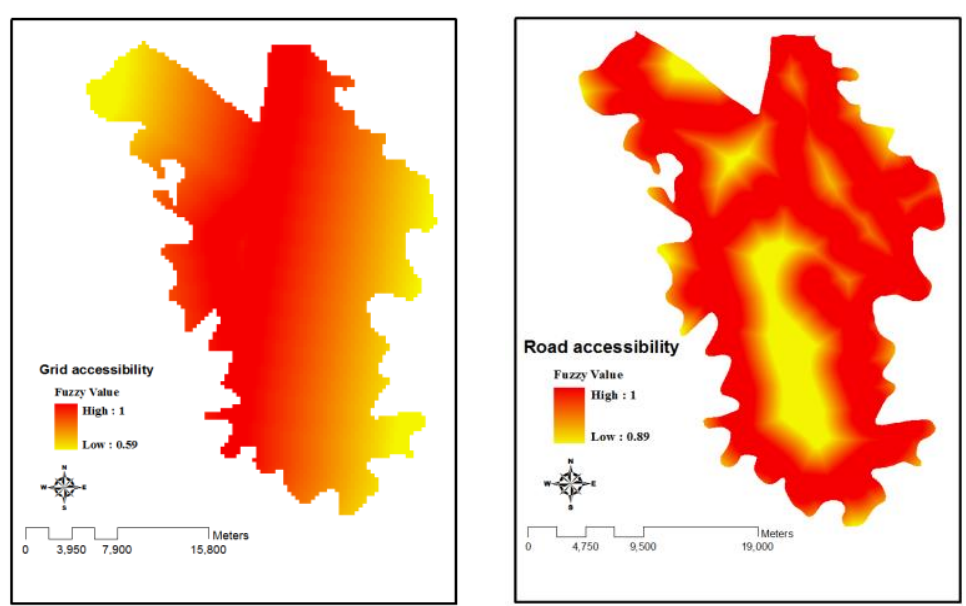

Figure 3. Fuzzy Layer of Criteria

Fuzzy value of multi criteria for exploitable area and spatial distribution of land suitability levels is illustrated in Figure 4. Based on fuzzy AHP model, exploitable area was classified into 3 classes including moderate, good and highly suitable for solar energy development (Figure 4). According to the model, it can be noticed that a big portion of exploitable area have the highly potential for solar energy development (76.58\% of exploitable area). Moderate suitability level have very small portion of exploitable area with $2.68 \%$.

Table 1. Total Generation Potential on Different Suitable Lands

\begin{tabular}{ccccc}
\hline Class & \multicolumn{3}{c}{ Area } & $\begin{array}{c}\text { Generation } \\
\text { potential } \\
(\mathrm{GWh} / \text { year })\end{array}$ \\
\cline { 2 - 4 } & $\left(\mathrm{m}^{2}\right)$ & $\begin{array}{c}\text { Exploitable } \\
(\%)\end{array}$ & $\begin{array}{c}\text { Shodirwan } \\
(\%)\end{array}$ & 430 \\
\hline Moderate suitable & 3305430 & 2.68 & 0.49 & 3340 \\
Good suitable & 25592380 & 20.75 & 3.79 & 12350 \\
Highly suitable & 94451290 & 76.58 & 13.98 & \\
\hline
\end{tabular}
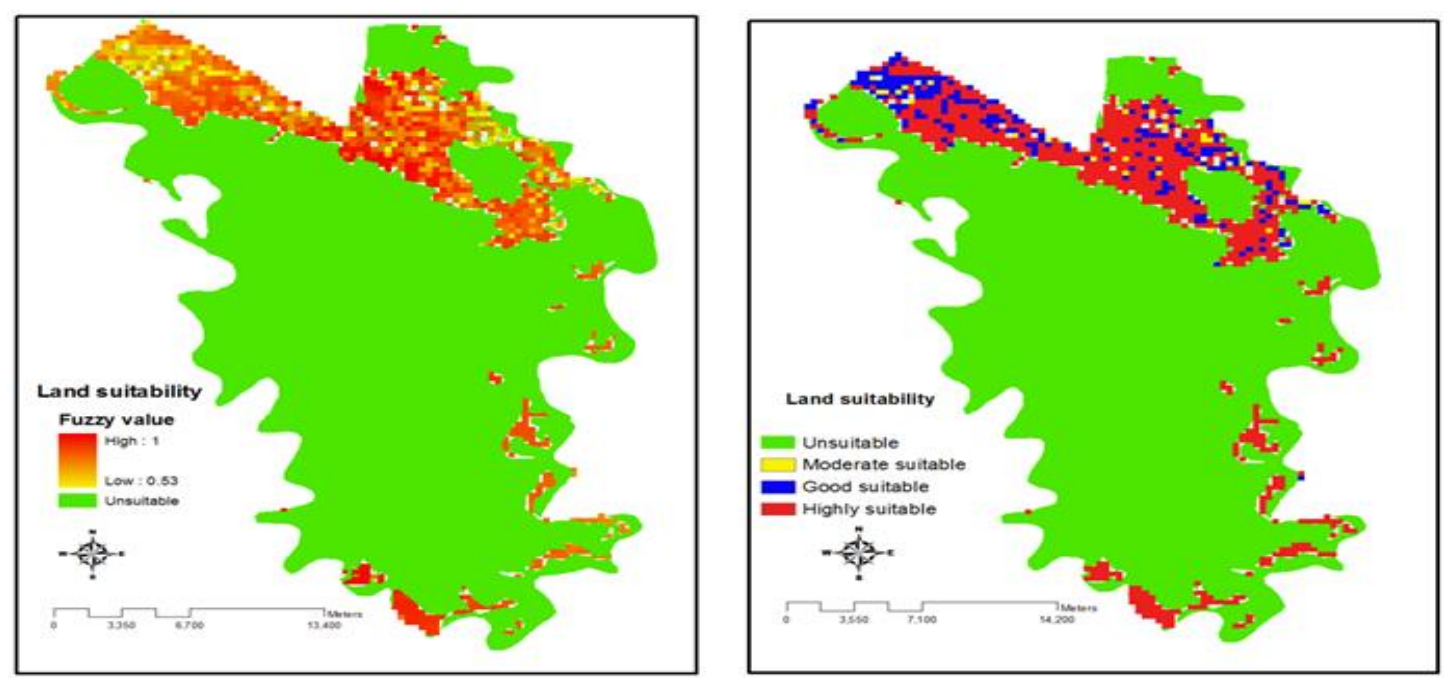

Figure 4. Spatial Distribution of Land Suitability Levels 


\section{Conclusion}

This study has described the application of a GIS-based spatial multi-criteria evaluation approach, in terms of the Fuzzy AHP module to assess the land suitability for solar farms implementation in Shodirwan region in Iran. GIS interpolation showed that annual solar insolation in Shodirwan is very good and can be used for potential solar farm locations. The average of solar insolation in the entire chosen region is $5.12 \mathrm{kWh} / \mathrm{m}^{2} /$ day and GIS overlay showed that $18.25 \%$ of the Shodirwan area is exploitable. Annual electricity production for exploitable area with conversion efficiency of $10 \%$ and area factor of $70 \%$ is roughly 16100 GWh. Land suitability analysis for solar farms implementation was carried out and overlay results obtained from the analysis of the resultant maps showed that $13.98 \%$ of the total land area demonstrate a high suitability level. It was found that the region has a very high technical potential for implementing solar forms to generate power. The total annual electricity generation potential from both highly and good suitability level is roughly $15690 \mathrm{GWh}$.

\section{Acknowledgements}

This research was supported by University of Tehran. The authors also would like to thank Iran Meteorological Organization, Renewable Energies Organization of Iran (SUNA), Jahad Agriculture Organization of Khuzestan province and Iran National Cartographic Center for providing the data for this research study.

\section{References}

[1] L. Bergamasco and P. Asinari, "Scalable methodology for the photovoltaic solar energy potential assessment based on available roof surface area: Application to Piedmont Region (Italy)," Solar Energy, vol. 85, (2011), pp. 1041-1055.

[2] D. Fadai, "Utilization of renewable energy sources for power generation in Iran," Renewable and Sustainable Energy Reviews, vol. 11, (2007), pp. 173-181.

[3] A. Asakereh, M. J. Shiekhdavoodi and A. Akram, "Investigation of Energy Consumption in Agriculture Sector of Iran and their Effect on Air Pollution and Social Cost", Research Journal of Applied Sciences Engineering and Technology, vol. 2, no. 5, (2010), pp. 401-406.

[4] A. Ghorashi and A. Rahimi, "Renewable and non-renewable energy status in Iran: Art of know-how and technology-gaps," Renewable and Sustainable Energy Reviews, vol. 15, (2011), pp. 729-736.

[5] A. Asakereh, M. Safaienejad and M. Sami, "Energy and economic analysis of dry farming chickpea in Iran a case study: Lorestan province", Journal of Agricultural Technology, vol. 7, no. 3, (2011), pp. 547-555.

[6] F. Atabi, "Renewable energy in Iran: Challenges and opportunities for sustainable development," International Journal of Environmental Science \& Technology, vol. 1, no. 1, (2004), pp. 69- 80.

[7] A. K. Hossain and O. Badr, "Prospects of renewable energy utilisation for electricity generation in Bangladesh,” Renewable and Sustainable Energy Reviews, vol. 11, (2007), pp. 1617-1649.

[8] O. O. Alabi, "An investigation on using GIS to prospect for renewable energy in Nigeria. University of Missouri Kansas. Phd thesis, (2010).

[9] Y. Charabi and A. Gastli, "PV site suitability analysis using GIS-based spatial fuzzy multi-criteria evaluation", Renewable Energy, vol. 36, (2011), pp. 2554-2561.

[10] T. A. Yanar and Z. Akyurek, "The enhancement of the cell-based GIS analyses with fuzzy processing capabilities”, Information Sciences, vol. 176, (2006), pp. 1067-1085.

[11] S. M. J. Baban and T, Parry, "Developing and applying a GIS assisted approach to locating wind farms in the UK," Renewable Energy, vol. 24, (2001), pp. 59-71.

[12] J. Byrne, A. Zhou, B. Shen and K. Hughes, "Evaluating the potential of small-scale renewable energy options to meet rural livelihoods needs: a GIS - and lifecycle cost-based assessment of Western China's options," Energy Policy, vol. 35, (2007), pp. 4391-4401.

[13] M. Arancibia, "The use of geographic information systems- GIS in strategic planning of energy resources," Polis. Revista de Universidad Bolivariana, vol. 7, no. 20, (2008), pp. 227-238.

[14] R. Luerssen, "Offshore Wind Session, Mapping and GIS Analysis in support of Clean Energy Development Offshore in Virginia," Virginia Coastal Energy Research Consortium, James Madison University, (2008). 
[15] J. Dominguez and I. P. Pascua, "GIS tool for rural electrification with renewable energies in Latin America, geows," International Conference on Advanced geographic information systems and web Services, (2009), pp. $171-176$.

[16] A. Simao, P. J, Densham and M. M, Haklay, "Web-based GIS for collaborative planning and public participation: an application to the strategic planning of wind farm sites", Journal of Environmental Management, vol. 90, (2009), pp. 2027-2040.

[17] T. Wakeyama and S. Ehara, "Renewable energy potential evaluation and analysis for use by using GIS -a case study of Northern-Tohoku area and Tokyo metropolis, Japan", International Journal of Environmental Science and Development, vol. 1, no. 5, (2010), pp. 446- 453.

[18] A. N. Arnette and C. W. Zobel, "Spatial analysis of renewable energy potential in the greater southern Appalachian mountain", Renewable Energy, vol. 36, (2011), pp. 2785-2798.

[19] A. Asakereh, M. Omid, R. Alimardani and F. Sarmadian, "Spatial Analysis the Potential for Energy Generation from Crop Residues in Shodirwan, Iran", International Journal of u- and e- Service, Science and Technology, vol.7, no.1, (2014), pp.275-284.

[20] P. A. Kwaku Kyem, "Of intractable conflicts and participatory GIS applications: the search for consensus amidst competing claims and institutional demands," Annals of the Association of American Geographers, vol. 94, no.1, (2004), pp. 37-57.

[21] R. Banai, "Land resource sustainability for urban development: spatial decision support system prototype", Environmental Management, vol. 36, no. 2, (2005), pp. 282-296.

[22] J. Malczewski, "Ordered weighted averaging with fuzzy quantifiers: GIS-based multicriteria evaluation for land-use suitability analysis", International Journal of Applied Earth Observation and Geoinformation, vol. 8, (2008), pp. 270-277.

[23] M. Dagdeviren, I. Yuksel and M. Kurt, "A fuzzy analytic network process (ANP) model to identify faulty behavior risk (FBR) in work system", Safety Science, vol. 46, (2008), pp. 771-783.

[24] J. J. Wang, Y. Y. Jing, C. F. Zhang, G. H. Shi and X. T. Zhang, "A fuzzy multi-criteria decision-making model for trigeneration system”, Energy Policy, vol. 36, (2008), pp. 3823-3832.

[25] S. Imoto, Y. Yabuuchi and J. Watada, "Fuzzy regression model of R\&D project evaluation", Applied Soft Computing, vol. 8, (2008), pp. 1266-1273.

[26] T. Kaya and C. Kahraman, "Multicriteria renewable energy planning using an integrated fuzzy VIKOR \& AHP methodology: The case of Istanbul", Energy, vol. 35, (2010), pp. 2517-2527.

[27] D. Y. Chang, "Theory and methodology: applications of the extent analysis method on fuzzy AHP", European Journal of Operational Research, vol. 95, no. 3, (1996), pp. 649-655.

[28] L. A. Zadeh, "Fuzzy sets", Information and Control, vol. 8, (1965), pp. 338-353.

[29] E. Tolga, M. Demircan and C. Kahraman, "Operating system selection using fuzzy replacement analysis and analytic hierarchy process", International Journal of Production Economics, vol. 97, (2005), pp. 89-117.

[30] F. Sheikhi, F. Sheikhi and F. Sheikhi, "Using Fuzzy Analytical Hierarchy Process for Selecting the Native and Non-Native Music Portfolio in Reducing of Stress," Advances in Natural and Applied Sciences, vol. 6, no. 2, (2012), pp. 100-109.

[31] A. Kengpol, P. Rontlaong and M. Tuominen, "A Decision Support System for Selection of Solar Power Plant Locations by Applying Fuzzy AHP and TOPSIS: An Empirical Study”, Journal of Software Engineering and Applications, vol. 6, (2013), pp. 470-481.

[32] S. K. Lee, G. Mogi and K. S. Hui, "A fuzzy analytic hierarchy process (AHP)/data envelopment analysis (DEA) hybrid model for efficiently allocating energy R\&D resources: In the case of energy technologies against high oil prices", Renewable and Sustainable Energy Reviews, vol. 21, (2013), pp. 347-355.

[33] Y. L. Hsu, C. H. Lee and V. B. Kreng, "The application of Fuzzy Delphi Method and Fuzzy AHP in lubricant regenerative technology selection," Expert Systems with Applications, vol. 37, (2010), pp. 419-425.

[34] T. L. Saaty, "The analytic hierarchy process," McGraw-Hill, New York, (1980).

[35] NREL-GIS, "Geographic information systems data. Golden," CO: National Renewable Energy Laboratory, (2003).

[36] Energy Balance, Iran Ministry of Energy, Deputy of Electricity and Energy Affairs, (2009). 
International Journal of Advanced Science and Technology Vol.68 (2014) 